\title{
BIOLOGICAL CONTROL OF HAEMONCHUS CONTORTUS BY FUNGAL ANTAGONISTS IN SMALL RUMINANTS
}

\author{
KHATTAK, B. ${ }^{1 *}-$ SAFI, A. U. R. ${ }^{1}-$ SindhU, Z. U. D. ${ }^{2}-$ ATTAULlah, M. ${ }^{3}-$ JAMAL, ${ }^{1}{ }^{1}-$ \\ KHAN, T. A. ${ }^{1}-$ HUSSAIN, M. ${ }^{1}-$ ANJUM, S. I. ${ }^{4}-$ ISRAR, M. ${ }^{5}-$ KHAN, I. A. ${ }^{6}$ \\ ${ }^{I}$ Department of Microbiology, Kohat University of Science and Technology, Pakistan \\ ${ }^{2}$ Department of Parasitology, University of Agriculture Faisalabad, Pakistan \\ ${ }^{3}$ Department of Zoology, University of Malakand \\ ${ }^{4}$ Department of Zoology, Kohat University of Science and Technology, Pakistan \\ ${ }^{5}$ Pakistan Science Foundation Islamabad, Pakistan \\ ${ }^{6}$ Department of Weed Science, The University of Agriculture Peshawar, Pakistan \\ *Corresponding author \\ e-mail: baharkk75@gmail.com; phone: +92-33-4907-3552 \\ (Received $10^{\text {th }}$ May 2018; accepted $5^{\text {th }}$ Jul 2018)
}

\begin{abstract}
Haemonchus contortus is a highly pathogenic nematode that causes haemonchosis in ruminants. As $H$. contortus is reported to be resistant to anthelmintic drugs, biological control might be the alternative approach. The study was conducted in Pakistan on different parameters to control $\mathrm{H}$. contortus biologically by fungi. Alternaria alternata, Fusarium oxysporum, Aspergillus niger, Trichoderma harzianum and Ochroconis gallopava were isolated from the feces and abomasa of infected domestic sheep (Ovis aries) and goats (Capra aegagrus hircus). Different concentrations of the extracted spore-free cultures of these fungi were applied on eggs, larvae and adults of $H$. contortus for eggs hatching inhibition assay, larval mortality assay and adult mortality assay. In eggs hatching inhibition assay, the higher concentrations i.e. $100 \%$ and $50 \%$ of A. alternata, F. oxysporum, A. niger, T. harzianum and $O$. gallopava caused $100 \%$ inhibition of eggs. In adult mortality assay, all the culture filtrates caused no mortality in the first and second hour while in the third hour of the post treatment mortality varied with concentrations. In larval mortality assay, higher concentrations i.e. $100 \%$ and $50 \%$ of T. harzianum and A, niger caused $100 \%$ mortality of $\mathrm{L}_{3}$ larvae of $H$. contortus. All the extracted spore-free cultures significantly caused eggs hatching inhibition. Higher concentrations of Trichoderma and Aspergillus significantly caused larval mortality $(100 \%)$ while adult mortality assays were dose and time dependent and insignificantly caused adult mortality of $H$. contortus.
\end{abstract}

Keywords: nematode parasite, haemonchosis, biocontrol, fungal extracts, egg hatch assay, adult mortality assay

\section{Introduction}

Livestock plays an important role in the economy of Pakistan. Agriculture contributes $21 \%$ in national gross domestic product (GDP) in which share of livestock is $11.9 \%$. The estimated population of domestic sheep (Ovis aries) was 29.1 million while domestic goats (Capra aegagrus hircus) were 66.6 million during 2013-14. According to a survey in Pakistan, about 45000 tons of meat was obtained from sheep during the year 20132014 (Economic Survey of Pakistan 2013-2014). Small ruminant livestock are highly susceptible to gastrointestinal nematodes (GINs). Among GINs, Haemonchus contortus, member of the family Trichostrongylidae (Radostits et al., 2006), is a highly pathogenic nematode parasite that causes haemonchosis in sheep and goat, an infection characterized 
by anemia, protein deficiency, bottle jaw and digestive disturbances throughout the world (Getachew et al., 2007; Bowman et al., 2009). It is estimated that an infected sheep with $5000 \mathrm{H}$. contortus worms may lose $250 \mathrm{ml}$ blood/day. Life cycle of $H$. contortus takes about 21 days to complete. $H$. contortus' life cycle is direct i.e. without the involvement of secondary host. Every adult female parasite lays between 5000-10,000 eggs/ day which are passed out in the feces (Hepworth, 2006) as shown in Figure 1.

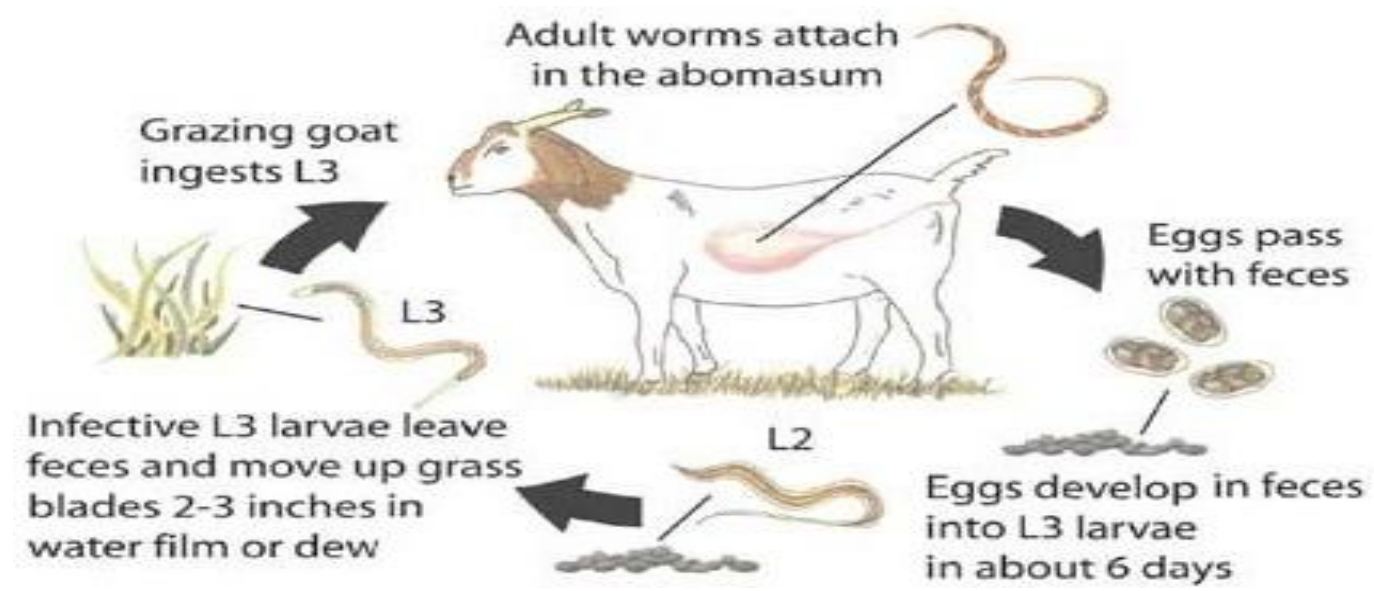

Figure 1. Life cycle of Haemonchus contortus. (Courtesy: pinterest.com)

As $H$. contortus is reported to be resistant to anthelmintic drugs (Miller et al., 1987; Sangster, 1999; Jackson and Coop, 2000) biological control might be the alternative approach. Many fungal species have been isolated from nematodes in which Duddingtonia flagrans has proven to be the most effective nematode-destroying fungus (Larsen et al., 1997) whose spores are found to survive while passing through the gastro-intestinal tract of grazing livestock (Hertzberg et al., 2001). Trichoderma, Fusarium and Acremonium have ovicidal effect on Toxacara canis ova (Maia Filho et al., 2011).

The present study was carried out in the light of previous work done to isolate and identify fungi from the feces of infected sheep and goats to evaluate the fungal filtrates' abilities of suppression the population of $H$. contortus on eggs hatching level, larval developmental level and adult level. These fungal extracts can be used as biological control against this parasite as a spray on grazing pastures or can be fed to animals in the form suspensions or pellets. Moreover, all fungi investigated in this study are of less toxigenic nature to animals' health so making them more suitable candidates for the purpose of the study.

\section{Materials and methods}

This research work carried out in laboratory of the Department of Microbiology, Kohat University of Science and Technology, Kohat, Pakistan.

\section{Sampling}

100 fecal samples of rectum from live goats and sheep and 100 abomasa samples from freshly slaughtered goats and sheep were collected from different areas of Kohat- 
Pakistan $\left(33^{\circ} 34^{\prime} 47.1^{\prime \prime N} 71^{\circ} 26^{\prime} 29.3^{\prime \prime} \mathrm{E}\right)$. The samples were analyzed for the detection of eggs (fecal samples) and worms (abomasa samples) of $H$. contortus as shown in Table 1. All the samples were processed in the department of Microbiology, Kohat University of Science and Technology Kohat, Pakistan.

Table 1. Samples collected and analyzed for the detection of eggs and worms of $H$. contortus

\begin{tabular}{c|c|c|c|c|c|c}
\hline Ruminants & Fecal samples & $\begin{array}{c}\text { Positive } \\
\text { (eggs seen) }\end{array}$ & $\begin{array}{c}\text { Negative } \\
\text { (no eggs) }\end{array}$ & Abomasa & $\begin{array}{c}\text { Positive } \\
\text { (worms seen) }\end{array}$ & $\begin{array}{c}\text { Negative } \\
\text { (no worms) }\end{array}$ \\
\hline Goats & 50 & 37 & 13 & 50 & 34 & 16 \\
Sheep & 50 & 31 & 19 & 50 & 41 & 9 \\
\hline Total & 100 & 68 & 32 & 100 & 75 & 25 \\
\hline
\end{tabular}

\section{Haemonchus contortus (eggs, adults and larvae)}

Eggs of $H$. contortus were identified and concentrated from fecal samples by simple test tube floatation method (Dryden et al., 2005), Mac Master counting chamber (Soulsby, 1968) and isolation of eggs from feces as described by (Hubert and Kerboeuf, 1992). Adult worms were collected from abomasa based on their typical barber pole appearance of female worms in a clean container as shown in Figure 2. Collected worms were washed with distilled water and concentrated in a container having freshly prepared phosphate buffer saline (PBS). Third stage larvae $\left(\mathrm{L}_{3}\right)$ were cultivated from the eggs recovered from adult female worms following the protocol of (Amarante, 2011) with slight modification. The $\mathrm{L}_{3}$ were morphologically differentiated and identified as described by (Van Wyk et al., 2004).

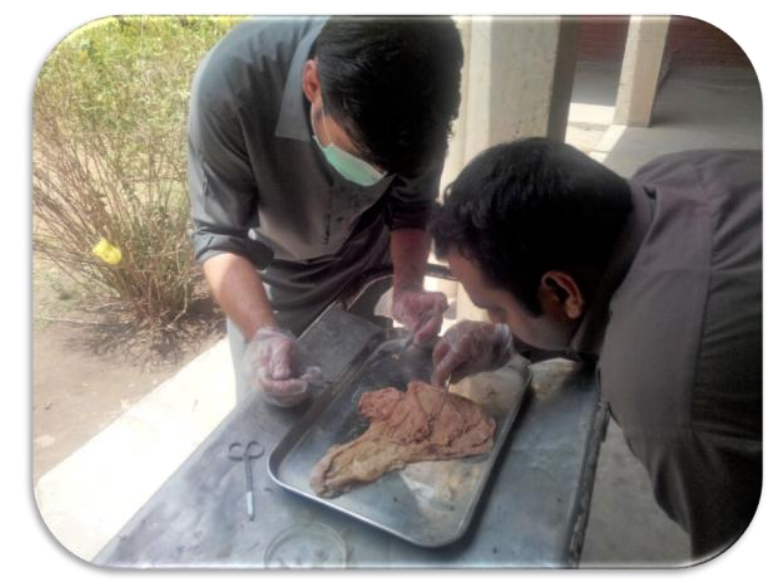

Figure 2. Harvesting worms from abomusam

\section{Fungi (isolation, identification and extraction)}

All positive fecal and abomasa samples were processed for the isolation of fungi. One-gram samples' contents were serially diluted and poured on Sabouraud dextrose agar (SDA) media for fungal growth. After $72 \mathrm{~h}$, the grown colonies were sub cultured to isolate pure cultures. For identification, both colony morphology and microscopic characteristics were deeply compared with the identification keys provided by (Navi et al., 1999) and (Larone and Larone, 1987). Among many other isolates, Alternaria 
alternata, Fusarium oxysporum, Aspergillus niger, Trichoderma harzianum and Ochroconis gallopava were the main isolates present in all positive samples. So these fungi were selected for fungal extracts.

For extraction, fungi in broth media were incubated in a shaker incubator for 7 days at $25{ }^{\circ} \mathrm{C}$ in dark. After 7 days, they were filtered by common Whatman filter papers and the filtrates were again filtered through Millex HA syringe driven filters $(0.45 \mu \mathrm{m})$. Different concentration i.e. $100 \%, 50 \%, 25 \%, 12.5 \%$ and $6.25 \%$ were made from each in phosphate buffer saline (PBS) and distilled water separately. Final filtrates were tested on potato dextrose agar (PDA) and SDA media to confirm the absence of fungal spores.

\section{Egg hatch assay (EHA)}

EHA was performed in triplicate following the protocol of (Coles et al., 1992) with slight modification. Isolated eggs were dissolved in $15 \mathrm{ml}$ distilled water with concentration adjusted to $100-200$ eggs/75 $\mu 1$. Then $75 \mu 1$ egg suspension was added to each well of a 24 -welled titration plate having $2.5 \mathrm{ml}$ of each concentration. For positive control, $0.025 \mathrm{mg} / \mathrm{ml}$ of Oxfendazole (Glaxo-welcome) was prepared in $0.3 \%$ dimethyl sulfoxide (DMSO). Wells having egg suspension and $2.5 \mathrm{ml}$ tap water with no extracts were used as negative control. The plate was incubated at $25{ }^{\circ} \mathrm{C}$ for $48 \mathrm{~h}$. After $48 \mathrm{~h}$, one drop of Lugol's oil was added to stop the reaction. Then the plate was observed under 10X of inverted microscope as shown in Figure 3. The percent hatching inhibition was observed as:

$$
\text { Hatching Inhibition }(\%)=\frac{P_{\mathrm{HI}} \text { Test }}{P_{\mathrm{HI}} \text { Total }} \times 100
$$

$P_{\mathrm{HI}}$ Test $=$ number of unhatched eggs, $P_{\mathrm{HI}}$ Total $=$ number of unhatched eggs + number of hatched eggs.

\section{Adult mortality assay (AMA)}

In AMA, ten worms were treated in triplicate to each filtrate concentration at room temperature. $25 \mu \mathrm{g} / \mathrm{ml}$ of Closantel was used as positive control. Phosphate buffer saline with worms and no fungal extracts were used as negative control. After each one hour of post treatment, all the plates were observed to check the mortality till all worms were dead in negative control. Because adult worms cannot survive without host longer than $9 \mathrm{~h}$. The percent mortality was calculated as:

$$
\text { Adult Mortality }(\%)=\frac{P_{\mathrm{AM}} \text { Test }}{P_{\mathrm{AM}} \text { Total }} \times 100
$$

$P_{\mathrm{AM}}$ Test $=$ number of dead worms, $P_{\mathrm{AM}}$ Total $=$ number of dead worms + number of live worms.

\section{Larval mortality assay (LMA)}

One $\mathrm{ml}$ of $\mathrm{L}_{3}$ larval suspension containing 10 larvae were added in triplicate to each well of titration plate having $2.5 \mathrm{ml}$ of fungal filtrates. Negative control well received 
only one $\mathrm{ml} \mathrm{L}_{3}$ suspension and $2.5 \mathrm{ml}$ phosphate buffer saline while positive control well received one $\mathrm{ml} \mathrm{L}_{3}$ suspension and $2.5 \mathrm{ml}$ closantel $(25 \mu \mathrm{g} / \mathrm{ml})$. The plate was incubated at room temperature for $3 \mathrm{~h}$. After $3 \mathrm{~h}$, the plate was observed under $10 \mathrm{X}$ of inverted microscope. Percent mortality was calculated as:

$$
\text { Larval Mortality }(\%)=\frac{P_{\mathrm{LM}} \text { Test }}{P_{\mathrm{LM}} \text { Total }} \times 100
$$

$P_{\text {LMTest }}=$ number of dead larvae, $P_{\text {LM }}$ Total $=$ number of dead larvae + number of live larvae.

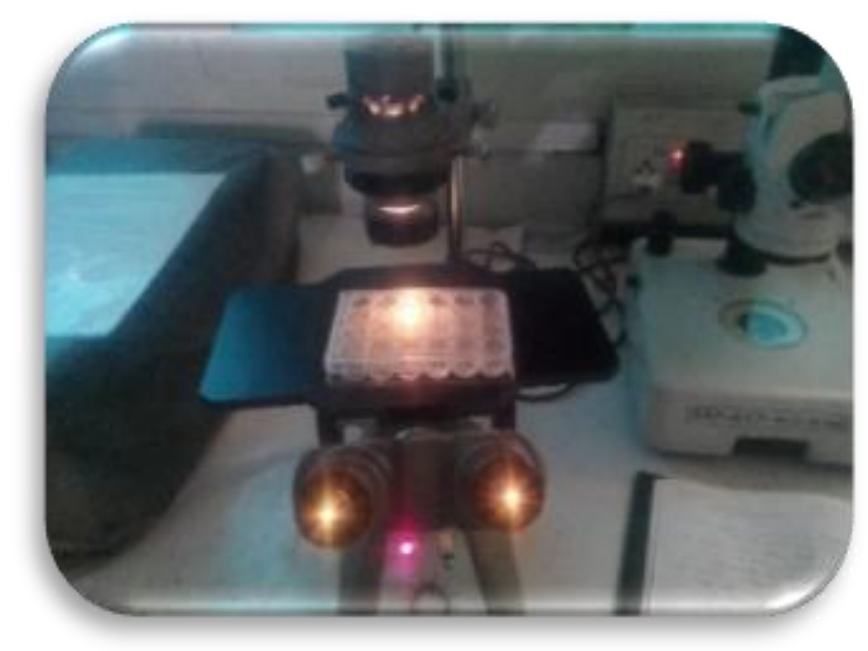

Figure 3. H. contortus' eggs under inverted microscope

\section{Statistical analysis}

Data obtained from bio-assays i.e. EHA, AMA and LMA were analyzed by ONE Way ANOVA and TWO-Way ANOVA through Statistix version 9 and GraphPad Prism version 5 software. The $p$ values $<0.05$ was considered significant.

\section{Results}

\section{Egg hatch assay}

After three days' incubation, the effect of different concentration of all fungal filtrates on eggs, were observed as shown in Figure 4. Higher concentrations i.e. 100\% and $50 \%$ of all filtrates caused $100 \%$ inhibition while inhibition by lower concentrations varied from specie to specie. There were $100 \%$ and no inhibition $(0 \%)$ in positive and negative control respectively.

\section{Adult mortality assay}

All concentrations of fungal filtrates treated with adult worms caused no mortality in the first three hours of post treatment. After three hours, the results were dose and time dependent and caused insignificant percent mortality as shown in Figure 5. 


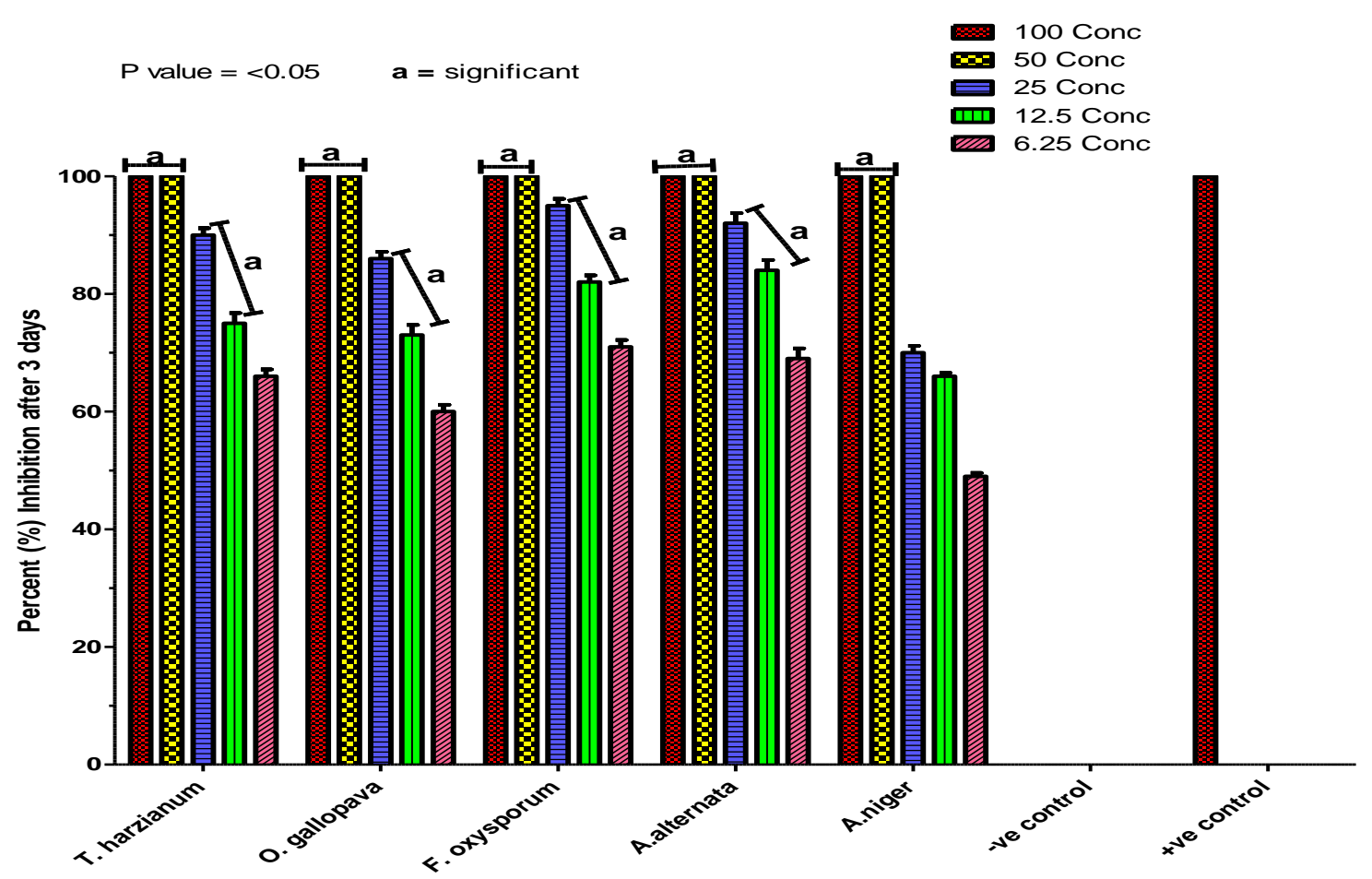

Figure 4. Percent inhibition of eggs hatching via fungal filtrates
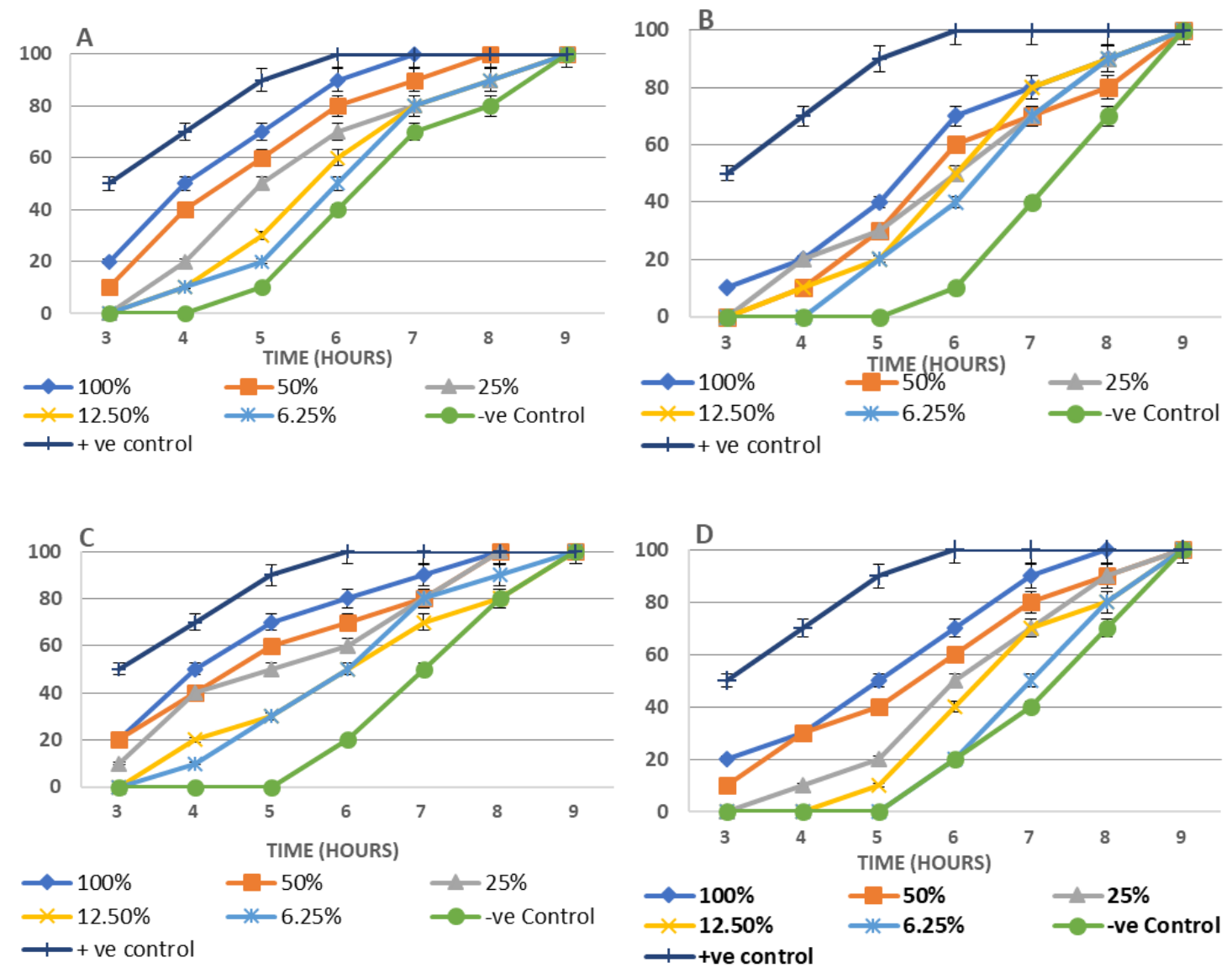


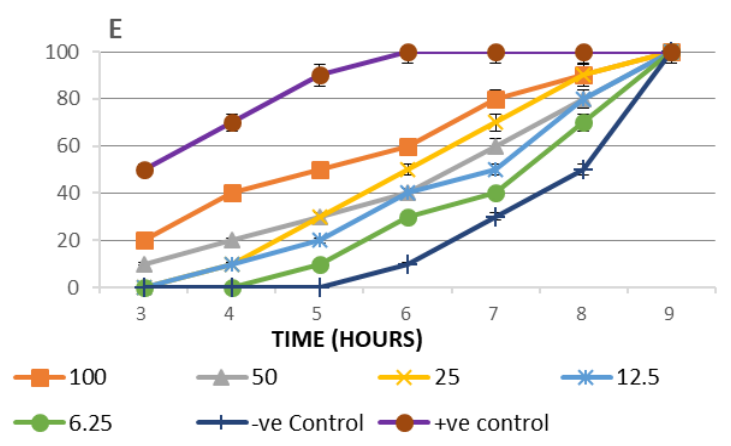

Figure 5. Adult worms' post-exposure against different concentration of fungal extracts. $\boldsymbol{A} . \boldsymbol{F}$. Oxysporum. B. A. alternate, $\boldsymbol{C}$. T. harzianum, D. A. niger, E. O. gallopava

\section{Larval mortality assay}

After $3 \mathrm{~h}$ post treatment of $\mathrm{L}_{3}$ larvae with fungal filtrates, higher concentrations i.e. $100 \%$ and $50 \%$ of the Trichoderma harzianum and Aspergillus niger caused $100 \%$ mortality while $100 \%$ concentrations of $F$. oxysporum and A. alternata caused $94 \%$ and $91 \%$ mortality respectively. Mortality caused by lower concentrations varied from species to species. $100 \%$ and no mortality in positive and negative control respectively as shown in Figure 6.

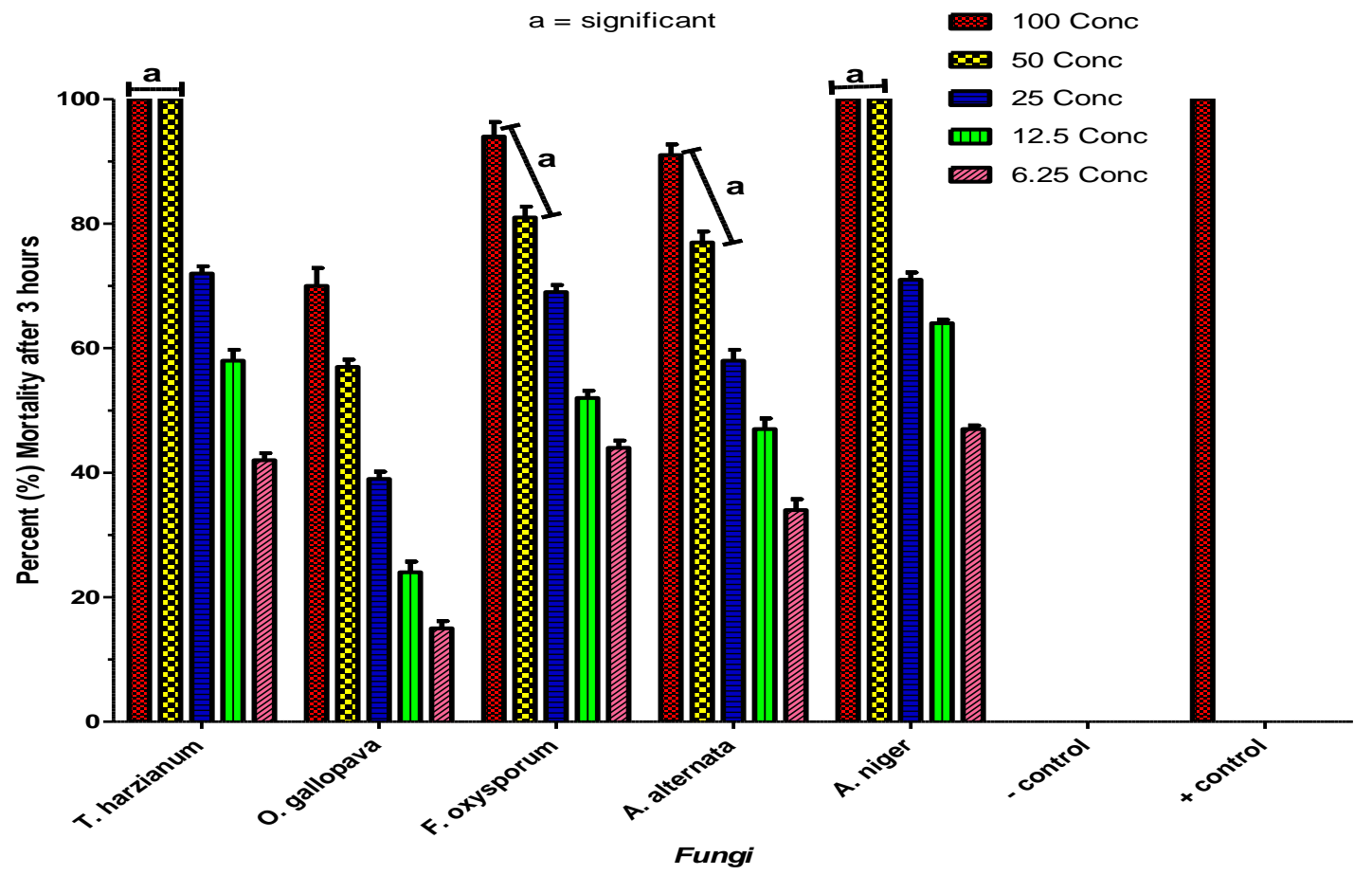

Figure 6. Percent mortality of $L_{3}$ larvae after 3 h post treatment

\section{Overall effect on Haemonchus contortus}

When the averages of all concentrations of each fungal treatment were analyzed by Least Significant Difference (LSD) and All-Pairwise Comparison (APC) tests, the 
results showed that all the tested fungi significantly affected all stages of $H$. contortus. Pairwise comparison of fungi showed that all fungi have equal significant effect on eggs of $H$. contortus while the significance of efficacy on adults and larvae varies from fungal to fungal species as shown in Figure 7.

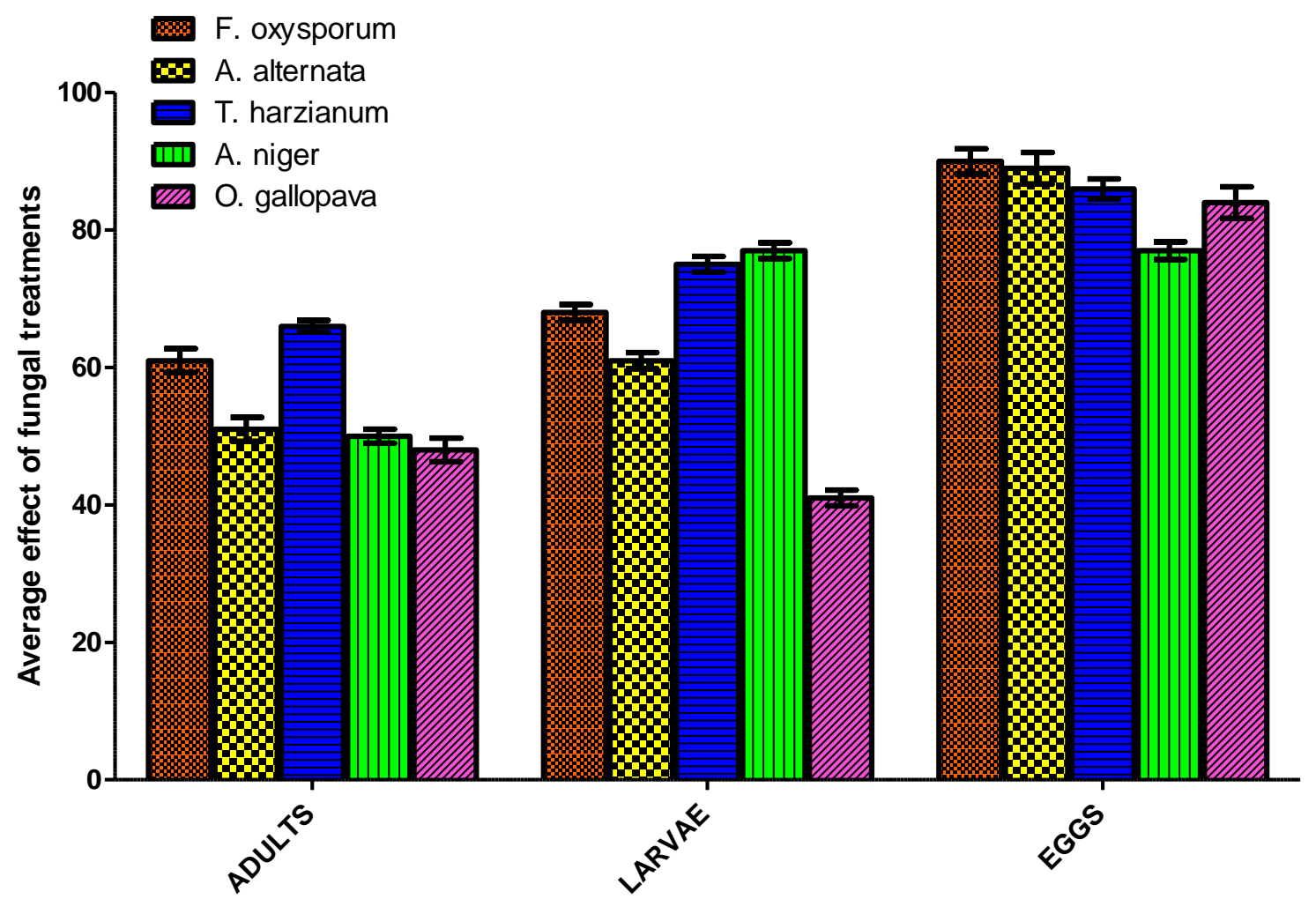

H. contortus stages

Figure 7. Average effect of fungal treatments on adults, larvae and eggs of $\mathrm{H}$. contortus

\section{Discussion}

To control Haemonchus contortus, common anthelmintics are applied but not enough to erase this parasite completely as it is reported to be resistant to all three broad spectrum families of anthelmintics viz. benzimidazole, lmidazothiazole and ivermectin and against drugs with narrow spectrum of activity such as salicylanilides anthelmintics (Kaplan and Vidyashankar, 2012). Keeping in view the importance of this blood sucker, there is need of alternative methods other than common anthelmintics to prevent sheep and goats from this highly dangerous nematode parasite. Biological control is an environment friendly alternative approach towards these nematodes. Among the microorganisms that parasitize on nematodes, fungi hold an important position in continuously eliminating parasitic nematodes (McSorley et al., 2008). About 70 genera and 200 species of fungi have been investigated that they are associated with nematode parasites. Till now, only a few of them are successful biocontrol agents (NordbringHertz et al., 2011).

In the present study, it was tried to investigate the fungal abilities biologically to suppress the $H$. contortus population on eggs hatching, larval and adult levels. Fungi 
were isolated from the feces of small ruminants and different concentrations of culture extracts were made from the isolated fungi. The spore-free cultures were applied on eggs, $\mathrm{L}_{3}$ larvae and adult worms of $H$. contortus to find out the percent inhibition and percent mortality. The results demonstrated that the higher concentrations i.e. $100 \%$ and $50 \%$ of all the extracted spore-free cultures of A. alternata, F. oxysporum, A. niger, T. harzianum and O. gallopava showed $100 \%$ eggs hatching inhibition of $H$. contortus. For the first time these fungi were applied on eggs of $H$. contortus although in previous studies many other nematophagous and filamentous fungi such as Arthrobotrys oligospora, A. musiformis, Cladosporium spp, A, flavus and Duddingtonia flagrans were treated with $H$. contortus eggs and showed similar results (Maia Filho et al., 2011). Also, different plant extracts have been reported previously to affect the biology of the parasitic eggs in the same ratio (Hounzangbe-Adote et al., 2005).

Adult worms of $H$. contortus in this study were treated with different concentrations i.e. $100 \%, 50 \%, 25 \%, 12.5 \%$ and $6.25 \%$ of the extracted spore-free cultures. The results were dose and time dependent as compared to a similar study conducted on animals grazing on pastures where D. flagrans was present which showed $97 \%$ efficacy of the fungus against this nematode parasite (Maria et al., 2011). Another study conducted by Chandrawathani and colleagues (Chandrawathani et al., 2003) in which they fed sheep during 24 days with either mineral blocks containing a dose of 500,000 chlamydospores/kg bw/day or pellets with the same fungal dose, and obtained a reduction in adults of $H$. contortus of $>95 \%$ in the first case and $98 \%$ in the second case.

The third stage larvae $\left(\mathrm{L}_{3}\right)$ of $H$. contortus in the present study were treated with different concentrations of each extracted spore-free cultures for three hours. After three hours, it was observed that higher concentrations i.e. $100 \%$ and $50 \%$ of the Trichoderma harzianum and Aspergillus niger caused $100 \%$ mortality in the $\mathrm{L}_{3}$ larvae while the mortality caused by lower concentrations of extracts varied from species to species. These results resemble a recent study conducted in Iran by Zarrin and colleagues in which they demonstrated that some saprophytic fungi spread in the environment can be effective in reducing the number of third stage larvae of Trichostrongylidae family. However, the rate of mortality was different because of the fungal species and isolates. They concluded that there was a considerable decrease in larvae population by Cladosporium spp. (98.8\%), Trichoderma spp. (98.5\%), and Aspergillus spp. (96.7\%) culture. Their results indicated great potential of using appropriate saprophyte fungi for biological control of $H$. contortus larvae in sheep (Zarrin et al., 2015). A similar study conducted on stage 3 larvae of $H$. contortus by Ivonneet al., 2011 investigated that mortality of infective larvae $\left(\mathrm{L}_{3}\right)$ by A. oligospora was $90.3 \%$, A. musiformis was $97 \%$, and M. thaumasium was $62.3 \%$ (Ivonne et al., 2011). Also, Menduza De Gives and Vazquez-prats investigated that A. oligospora, Monacrosporium acermatoum and A. robusta caused mortality of the population of $H$. contortus infective $\mathrm{L}_{3}$ larvae with $93.30 \%, 95.70 \%$ and $10.10 \%$, respectively (MendozaDe Gives and Vazquez-Prats, 1994).

\section{Conclusion and recommendations}

From the study, it is concluded that higher concentrations of all the extracted sporefree culture filtrates from the isolated fungi significantly caused eggs hatching inhibition. Higher concentrations of Trichoderma harzianum and Aspergillus niger significantly caused larval mortality (100\%) while adult mortality assays were dose and 
time dependent and insignificantly caused adult mortality of Haemonchus contortus. Keeping in view the importance of this problem and encouraging results obtained from the study, there is need to explore the chemistry of the fungal filtrates to find out their active compounds and their mechanism of actions (both in vitro and in vivo). The effects of these fungi at molecular level like DNA damage and genetic alterations in $H$. contortus need further explorations.

Acknowledgements. We sincerely acknowledge Pakistan Science Foundation Islamabad for providing us financial support with grant number (PSF/NSLP/KP-KUST-298). Also, thanks go to faculty and staff of Department of Microbiology, Kohat University of Science and Technology Kohat and Department of Parasitology, University of Agriculture Faisalabad for their Technical support.

\section{REFERENCES}

[1] Amarante, A. F. (2011): Why is it important to correctly identify Haemonchus species? Revista Brasileira de Parasitologia Veterinária 20(4): 263-268.

[2] Bowman, D. D. (2009): Georgis Parasitology for Veterinarians. $9^{\text {th }}$ ed. - Saunders Elsevier, St; Louis, pp. 161-162.

[3] Chandrawathani, P., Jamnah, O., Waller, P. J., Larsen, M., Gillespie, A. T., Zahari, W. M. (2003): Biological control of nematode parasites of small ruminants in Malaysia using the nematophagous fungus Duddingtonia flagrans. - Veterinary Parasitology 117(3): 173183.

[4] Coles, G. C., Bauer, C., Borgsteede, F. H. M., Geerts, S., Klei, T. R., Taylor, M. A., Waller, P. J. (1992): World Association for the Advancement of Veterinary Parasitology (WAAVP) methods for the detection of anthelmintic resistance in nematodes of veterinary importance. - Veterinary Parasitology 44(1): 35-44.

[5] De Souza, M. F., Vieira, N., Berne, J. A., Stoll, F. E., Nascente, P., Potter, L. (2013): Fungal ovicidal activity on Toxocara canis eggs. - Revista Iberoamricana de Micologia 30: 226-30.

[6] Dryden, M. W., Payne, P. A., Ridley, R., Smith, V. (2005): Comparison of common fecal flotation techniques for the recovery of parasite eggs and oocysts. - Veterinary Therapeutics 6(1): 15-28.

[7] Economic Survey of Pakistan (2013-2014): http://www.finance.gov.pk/survey_1314.html.

[8] Getachew, T., Dorchies, P., Jacquiet, P. (2007): Trends and challenges in the effective and sustainable control of Haemonchus contortus infection in sheep. - Parasite 14(1): 314.

[9] Hepworth, K., Neary, M., Hutchens, T. (2006): Managing Internal Parasitism in Sheep and Goats. - Purdue University Cooperative Extension Service, West Lafayette, IN, pp. $1-10$.

[10] Hertzberg, H., Larsen, M., Maurer, V. (2002): Biological control of helminths in grazing animals using nematophagous fungi. - Berliner und Munchener Tierarztliche Wochenschrift 115(7): 278-85.

[11] Hounzangbe-Adote, M. S., Paolini, V., Moutairou, I. K., Hoste, H. (2005): In vitro effects of four tropical plants on three life-cycle stages of the parasitic nematode, Haemonchus contortus. - Research in Veterinary Science 78(2): 155-160.

[12] Hubert, J., Kerbouef, D. (1992): A micro larval development assay for the detection of anthelmintic resistance in sheep nematodes. - Veterinary Record 130(20): 442-446.

[13] Ivonne, C. A. G., de Gives, P. M., Hernández, E. L., Arellano, E. L., Valero Coss, R. O., Velázque, M. H. (2011): Nematophagous fungi (Orbiliales) capturing, destroying and 
feeding on the histotrophic larvae of Haemonchus contortus (Nematoda: Trichostrongylidae). - Revista Mexicana De Micología 33: 29-35.

[14] Jackson, F., Coop, R. L. (2000): The development of anthelmintic resistance in sheep nematodes. - Parasitology 120: 95-107.

[15] Kaplan, R. M., Vidyashankar, A. N. (2012): An inconvenient truth: Global warming and anthelmintic resistance. - Veterinary Parasitology 186(1): 70-80.

[16] Larone, D. H. (1987): Medically Important Fungi. A Guide to Identification. - Elsevier Science Ltd., Washington DC.

[17] Larsen, M., Nansen, P., Grønvold, J., Wolstrup, J., Henriksen, S. A. (1997): Biological control of gastro-intestinal nematodes-facts, future, or fiction. - Veterinary Parasitology 72(3): 479-85.

[18] María, F., Sagüés, L. A., Fusé, A., Fernández, S., Lucía, E. I., Fabiana, C. M., Carlos, A. S. (2011): Efficacy of an energy block containing Duddingtonia flagrans in the control of gastrointestinal nematodes of sheep. - Parasitology Research 109(3): 707-713.

[19] McSorley, R., Wang, K. H., Church, G. (2008): Suppression of root knot nematodes in natural and agricultural soils. - Applied Soil Ecology 39: 291-298.

[20] Menduza de Gives, P., Vazquez-prats, V. M. (1994): Reduction of Haemonchus contortus infective larvae by three nematophagous fungi in sheep faecal cultures. Veterinary Parasitology 55: 197-203.

[21] Miller, J. E., Hembry, F. G., Kearney, M. T., Williams, J. C., Stag, L. C., Sims, D. (1987): Efficacy of levamisole and netobimin against Haemonchus contortus in lambs in Louisiana. - American Journal of Veterinary Research 48(9): 1403-1406.

[22] Navi, S. S., Bandyopadhyay, R., Hall, A. J., Bramel-Cox, P. J. (1999): A pictorial guide for the identification of mold fungi on sorghum grain. - Information Bulletin no. 59 (in En., Summaries in En, Fr). International Crops Research Institute for the Semi-Arid Tropics. Patancheru 502324, Andhra Pradesh, India.

[23] Nordbring-Hertz, B., Jansson, H. B., Tunlid, A. (2011): Nematophagous Fungi. - In: eLS. John Wiley \& Sons Ltd, Chichester. http://www.els.net [doi: 10.1002/9780470015902.a0000374.pub3]

[24] Radostits, O. M., Gay, C. C., Hinchcliff, K. W., Constable, P. D. (2007): Veterinary Medicine. A Text Book of the Diseases of Cattle, Horses, Sheep, Pigs and Goats. Saunders Ltd., Philadelphia, USA pp. 20-65.

[25] Sangster, N. C. (1999): Anthelmintic resistance: past, present, and future. - International Journal for Parasitology 29(1): 115-124.

[26] Soulsby, E. J. (1982): Helminths, Arthropods and Protozoa of Domesticated Animals. Bailliere Tindall, London, pp. 248-250, 766-770.

[27] Van Wyk, J. A., Cabaret, J., Michael, L. M. (2004): Morphological identification of nematode larvae of small ruminants and cattle simplified. - Veterinary Parasitology 119(4): 277-306.

[28] Zarrin, M., Rahdar, M., Gholamian, A. (2015): Biological control of the nematode infective larvae of Trichostrongylidae family with filamentous fungi. - Jundishapur Journal of Microbiology 8(3): e17614. 